\title{
Effect of steel fiber on the crack permeability evolution and crack surface topography of concrete subjected to freeze-thaw damage
}

\author{
Wei ZENG ${ }^{\mathrm{a}}$, Yining DING ${ }^{\mathrm{a}}$, , Yulin ZHANG ${ }^{\mathrm{b}}$, Frank DEHN ${ }^{\mathrm{c}}$
}

${ }^{a}$ State Key Laboratory of Coastal and Offshore Engineering, Dalian University of Technology, Dalian

116024, China

${ }^{b}$ Centre of Mathematics, University of Minho, Braga 4700-052, Portugal

${ }^{c}$ Materials Testing and Research Institute, Karlsruhe Institute of Technology, Karlsruhe, D-76131, Germany

(1)

\section{Abstract}

This paper describes the steel fiber effect on the crack permeability and crack surface topography of concrete subjected to freeze-thaw damage. The sequential crack permeability of steel fiber reinforced concrete are investigated by a vacuum permeability set-up. The topographical analysis is applied on the crack surface by an invented 3-D laser scanning equipment. The results show that the crack permeability of concrete is less than the value predicted by the Poiseuille flow model and their difference decreases gradually with the crack widening. With increment of steel fiber dosage and freeze-thaw damage level, the effect of steel fiber on reducing the crack permeability becomes strong. Topographical analysis illustrates that both steel fiber and freeze-thaw damage enhance the roughness of concrete crack surface. The relationship between roughness number of crack surface and material permeability parameter $\alpha$ follows an exponential function, which can be employed to quickly estimate the crack permeability of concrete.

Keywords: Crack permeability; Crack surface topography; Freeze-thaw damage; Steel fiber; Concrete.

\footnotetext{
* Corresponding author. Tel.: +86 0411 84709756. E-mail: ynding@ hotmail.com (Y. Ding).
} 


\section{Introduction}

With the deterioration of concrete structures, durability is of great concern. For structures in cold regions, freeze-thaw damage is especially one of the main reasons of concrete deterioration $^{[1]}$. When water begins to freeze in a capillary pore, the increase in volume accompanying the freezing of the water requires a dilation of the cavity equal to $9 \%$ of the volume of frozen water or forcing of the amount of excess water out through the boundaries of the specimen. The hydraulic pressure (due to an increase in the specific volume of water on freezing in large pores) and osmotic pressure (due to salt concentration differences in the pore fluid) will induce the expansion of cement pastes. As a result of environmental exposure, disruptive pressures will be developed in a saturated specimen of paste. Cracks as well as micro-cracks occur and propagate. With the concrete deterioration caused by freeze-thaw damage, the cracks and micro-cracks interconnect ${ }^{[2]}$, a concrete structure loses its watertigthness, and becomes vulnerable to one or more processes of deterioration. The permeability is implicated in the mechanisms of expansion and cracking, and becomes a risk factor for concrete durability ${ }^{[3-5]}$.

In recent decades, some investigations have reported the dramatically influence of the crack on the water/gas transport properties of cement-based materials. Wang et al. ${ }^{[6]}$ employed the feedback controlled splitting tensile test to study the permeability of cracked concrete. The results showed that crack permeability increased with the increasing of crack width. When the crack width was more than $50 \mu \mathrm{m}$, the crack permeability of concrete increased rapidly. Aldea et al. ${ }^{[7]}$ used the same method to estimate the crack permeability of paste, mortar and concrete and indicated that the different types of matrix had an obvious influence on the crack geometry and the crack permeability. Rastiello et al ${ }^{[8]}$ investigated the trend of permeability evolution of cracked concrete specimens with crack opening under splitting tensile loading. Compared with crack permeability, the permeability of intact concrete matrix can be negligible. Rapoport et al. ${ }^{[9]}$ explored the relationship between crack permeability and crack width of cracked steel fiber reinforced concrete. The experimental results showed that the existence and propagation of macro cracks of concrete structures significantly enhanced crack permeability and accelerated the degradation of concrete. As such, the crack permeability 
plays a significant role in the serviceability and durability of concrete. Further, when the engineering/concrete structures is in the service life/condition, concrete in structures generally carries heavy load. The research on the crack permeability of concrete under loading ${ }^{[10]}$ is meaningful. However, the above relevant/mentioned research is very rare. Most of investigations $^{[6,7,9]}$ studied the crack permeability of cracked concrete after unloading. Such investigations are not consistent with the loading conditions of concrete in the engineering practice. Even more rare is the study on the cracked concrete under both cold weather and external loading, e.g. for hydraulic structure or port structures in North Asia or North America. There is still a lack of systematic investigations of the crack permeability of concrete subjected to freeze-thaw damage under loading.

As a result of crack propagation, the crack surface topography may reveal the corresponding crack permeability. Recent investigations have been conducted to analyze the relationship between the crack surface topography and the crack permeability. Ding et al. ${ }^{[11]}$ indicated that the addition of steel fiber decreased the crack permeability and increased the crack tortuosity and surface roughness by the feedback controlled splitting test and permeability test. Akhavan et al. ${ }^{[12]}$ and Mechtcherine et al. ${ }^{[13]}$ investigated the influence of crack tortuosity and surface roughness on crack permeability using the Poiseuille flow model. The experimental results indicated that with the increasing of crack tortuosity and surface roughness, the crack permeability of concrete decreased gradually. The review of literature shows that the crack permeability could be correlated with the crack surface topography, and the relationship between crack permeability and crack surface topography should be further explored. Commonly, the set-up of permeability test is complex and the permeability testing is very time consuming. Compared with the permeability test, the crack surface topography can be analyzed more quickly, accurately and efficiently. For this reason, the evaluation of crack permeability based on the crack surface topography can provide a new way to analyze the crack permeability.

Fiber reinforced concrete is an increasingly popular constructional composite material ${ }^{[14]}$, especially steel fiber reinforced concrete (SFRC). SFRC not only shows higher toughness and energy absorption than that of plain concrete, but the addition of steel fibers also changes the 
crack surface topography and limits the crack width of concrete ${ }^{[11,15-19]}$. In order to analyze the influence of steel fiber on crack permeability of concrete subjected to freeze-thaw damage, a series of tests were conducted: (a) the rapid freeze-thaw test was employed to induce the freeze-thaw damage of different samples, (b) the splitting tensile test was adopted to investigate the relationship between the crack opening displacement at the mid height of the samples $\left(C O D_{\mathrm{m}}\right)$ and the effective cracked cross-section area of crack, (c) the permeability test subjected to splitting loading was carried out (Fig. 6) to evaluate the crack permeability of concrete under external loading, (d) an invented 3-D laser scanning equipment (Fig. 8) was introduced to obtain the topographical information of crack surface of different samples. Furthermore, the Poiseuille flow model, modified factor $\xi$ and material permeability parameter $\alpha$ were employed to analyze the crack permeability of cracked concrete. The roughness number $(R N)$ was applied to analyze the effect of steel fiber on the crack surface topography. The relationship between $R N$ of crack surface and material permeability parameter $\alpha$ was set up.

\section{Experiment}

\subsection{Materials}

In this program, the base mix design of concrete without fiber reinforcement was as follows: Portland cement CEM II/A-M 42.5R $\mathrm{R}^{[20]} 390 \mathrm{~kg} / \mathrm{m}^{3}$; fly ash $155 \mathrm{~kg} / \mathrm{m}^{3}$; fine aggregate $822 \mathrm{~kg} / \mathrm{m}^{3}(0-5 \mathrm{~mm})$; coarse aggregate $848 \mathrm{~kg} / \mathrm{m}^{3}(5-10 \mathrm{~mm})$; water $272.5 \mathrm{~kg} / \mathrm{m}^{3}$; super plasticizer $5.5 \mathrm{~kg} / \mathrm{m}^{3}$. Widely used steel fiber was added into the concrete samples. The geometry and properties of steel fiber are illustrated in Fig. 1 and Table 1. The fiber dosages of specimens were $0 \mathrm{~kg} / \mathrm{m}^{3}, 20 \mathrm{~kg} / \mathrm{m}^{3}, 40 \mathrm{~kg} / \mathrm{m}^{3}$ and $60 \mathrm{~kg} / \mathrm{m}^{3}$, respectively. 


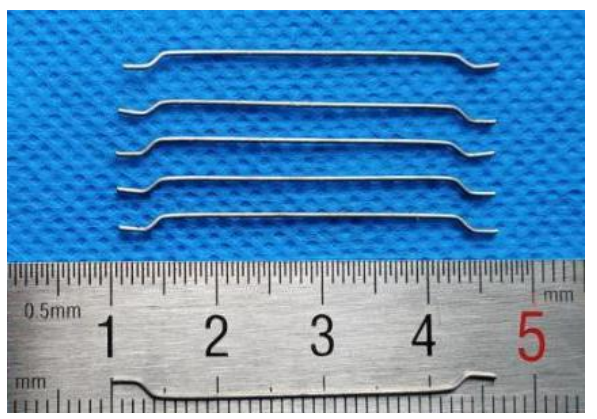

Fig. 1. Geometry of steel fiber

Table 1

111 Properties of steel fiber

\begin{tabular}{ccccccc}
\hline Type & $\begin{array}{c}\text { Length } \\
(\mathrm{mm})\end{array}$ & $\begin{array}{c}\text { Diameter } \\
(\mathrm{mm})\end{array}$ & $\begin{array}{c}\text { Aspect } \\
\text { ratio }\end{array}$ & $\begin{array}{c}\text { Tensile strength } \\
(\mathrm{MPa})\end{array}$ & $\begin{array}{c}\text { E-Modulus } \\
(\mathrm{GPa})\end{array}$ & $\begin{array}{c}\text { Number } \\
(\text { Pieces/kg) }\end{array}$ \\
\hline Steel fiber & 35 & 0.54 & 65 & 1345 & 200 & 14500 \\
\hline
\end{tabular}
of different samples after freeze-thaw cycles were beams with the size of $100 \mathrm{~mm} \times 100 \mathrm{~mm}$ $\times 400 \mathrm{~mm}$. Cylindrical specimens with the size of $100 \mathrm{~mm}$ diameter $\times 50 \mathrm{~mm}$ thickness were used in the permeability test. A forced mixer was used for mixing. Each type of samples was cast in beam molds and cylinder molds (100 $\mathrm{mm}$ in diameter and $250 \mathrm{~mm}$ in thickness), respectively. Specimens were de-molded after $24 \mathrm{~h}$ and kept in a standard curing room for 28 days. Before permeability test, the diamond blade saw was introduced and the cylinders were cut to obtain $50 \mathrm{~mm}$ thick cylindrical specimens. Forty eight cylindrical specimens and twelve

122 beam specimens were prepared for each type of samples.

After 28-day curing, both the cylindrical specimens and the beam specimens were exposed to freeze-thaw cycles in a temperature controlled chamber. Rapid freeze-thaw test 

was conducted according to the ASTM C666 ${ }^{[21]}$. One cycle of freeze-thaw lasted about $3.5 \mathrm{~h}$. The temperature-time relations of the temperature controlled chamber and the specimen center are shown in Fig. 2. In order to quantify the freeze-thaw damage of specimens, the $R D M E$ value of beam specimens (Eq. (1)) was used to monitor the damage development.

$$
R D M E=\left(\frac{f_{\mathrm{n}}}{f_{1}}\right)^{2} \times 100 \%
$$

where $f_{\mathrm{n}}$ is the fundamental transverse frequency after $\mathrm{n}$ freeze-thaw cycles, $f_{1}$ is the initial fundamental transverse frequency. The fundamental transverse frequencies of specimens were tested using a forced resonance apparatus.

When the RDME value of beam specimens reached the predetermined ratio $(100 \%, 90 \%$, $75 \%$ and 60\%), which was considered as four freeze-thaw damage levels, the rapid freeze-thaw test of the corresponding cylindrical specimens was stopped. The specimens without freeze-thaw damage were adopted as the reference specimens.

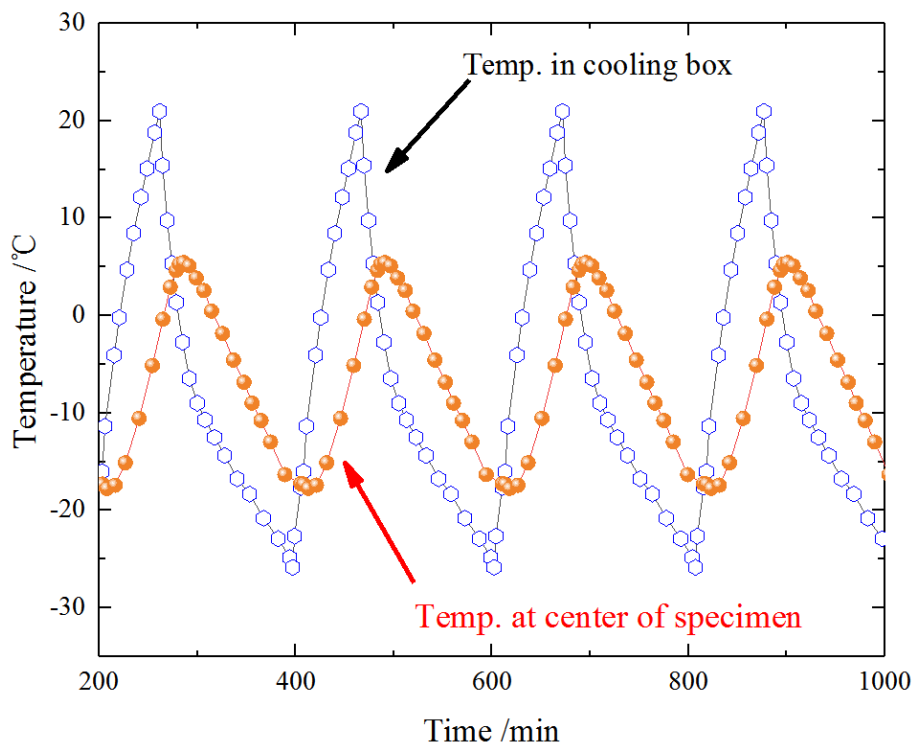

Fig. 2. Temperature-time relations of the temperature controlled chamber and the center of the 
In the following, the cylindrical specimens are characterized by the fiber dosage of FRC and the freeze-thaw damage levels $(R D M E=100 \%, 90 \%, 75 \%$ and $60 \%)$, for instance, a cylindrical SF20 specimen with RDME of 90\% is called "SF20-90".

\subsection{Splitting tensile test}

Because the specimen was sealed by the waterproof tape, silicon rings and vessels in permeability test (see Fig. 6), it was hardly to observe directly the crack geometry and evaluate the effective cracked cross-section area $\left(A_{\mathrm{f}}^{\text {eff }}\right)$ on the specimen surfaces. But the diameter variation $\left(\Delta_{\mathrm{d}}\right)$ of specimens was easily measured. For this reason, before the permeability test, the splitting tensile test without flow measurement has been conducted to measure the $\Delta_{\mathrm{d}}$ and the cracked cross-section area of samples with the crack opening, and then the crack opening displacement $\left(C O D_{\mathrm{m}}\right)$ at the mid height of the specimen (see Eq. (3)) and the effective cracked cross-section area $\left(A_{\mathrm{f}}^{\text {eff }}\right)$ of samples (see Fig. 7) were calculated. Then, the statistical relationships between the $C O D_{\mathrm{m}}$ and the $A_{\mathrm{f}}^{\text {eff }}$ were obtained by means of the splitting test and applied to evaluate indirectly the $A_{\mathrm{f}}^{\text {eff }}$ of samples in the permeability test (see Fig. 5 and Table 2).

The splitting tensile test (Fig. 3) was performed with a constant deformation rate of 0.012 $\mathrm{mm} / \mathrm{min}$, which was the same with that of permeability test under loading. As mentioned by Wang et al. ${ }^{[6]}$, cracks generally opened on one face and then propagated towards the other face. Hence, four LVDTs were employed to measure the diameter variation $\Delta_{\mathrm{d}}$ which were normal to the load axis along the two opposite sides of the specimens. They were symmetrically placed with respect to the median vertical plane of the sample. Each diameter variation $\Delta_{\mathrm{d}}$ was the sum of two opposite displacements. Due to the asymmetrical crack openings, the average value of two pairs diameter variations can be calculated by Eq. (2).

$$
\Delta_{\mathrm{d}}=\frac{\Delta_{\mathrm{df}}+\Delta_{\mathrm{db}}}{2}
$$


In order to acquire the crack opening displacement $\left(C O D_{\mathrm{m}}\right)$ at the mid height of the 171 specimen, the elastic deformation of the specimens under loading should be considered. 172 Rastiello et al. ${ }^{[8]}$ have indicated that the two pieces of specimens can be considered as two 173 undamaged elastic blocks, the elastic diameter variation $\Delta_{\mathrm{d}, \mathrm{e}}$ can be calculated by the function 174 of the splitting tensile load and the slope of load and diameter variation in the pre-crack phase. 175 So the $C O D_{\mathrm{m}}$ can be calculated by Eq. (3):

$$
C O D_{\mathrm{m}}=\Delta_{\mathrm{d}}-\Delta_{\mathrm{d}, \mathrm{e}}
$$

During the splitting loading process, the sequential geometry of cracked cross-section of two faces was recorded by two cameras, as shown in Fig. 3. The total crack was identified by means of a curve-tracing tool in the Image-Pro Plus (image analysis software). After digitization processing of image, the area of cracked cross-section could be calculated (see 181 Fig. 4).

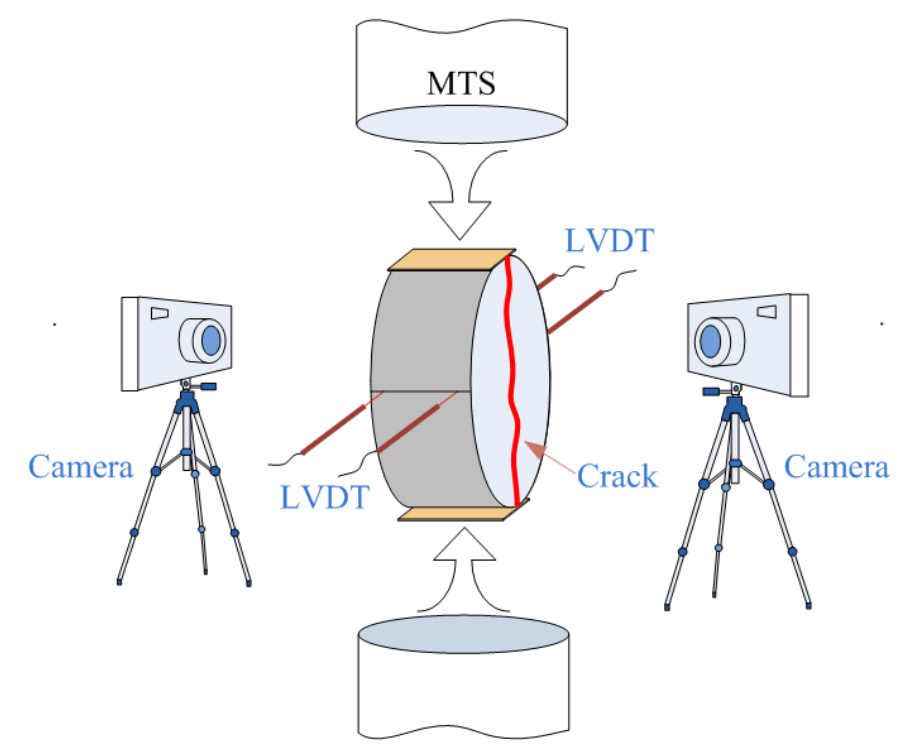




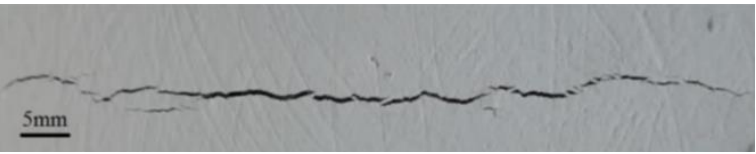

(a)

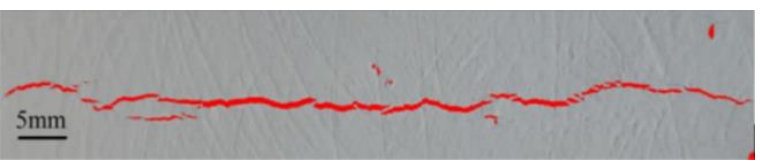

(b)

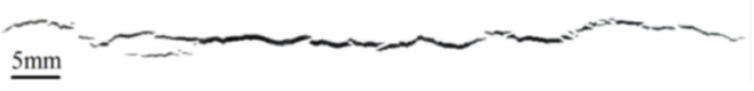

(c)

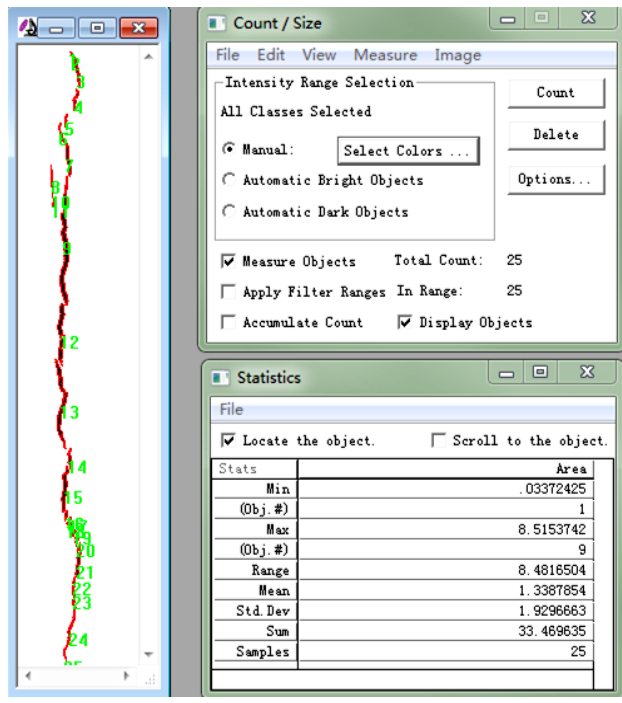

(d)
187

Fig. 5 and Table 2 show that the relationship between $C O D_{\mathrm{m}}$ and the effective cracked cross-section area $\left(A_{\mathrm{f}}^{\text {eff }}\right)$ of samples corresponds well with the linear function and a similar result was also reported by Rastiello et al. ${ }^{[8]}$ It implies that when the $C O D_{\mathrm{m}}$ is known, $A_{\mathrm{f}}^{\text {eff }}$ can be assessed by the linear function. The relationship can be expressed in Eq. (4):

$$
\mathrm{Y}=c \cdot \mathrm{X}
$$

where $c$ is a parameter corresponding to the type of samples and the freeze-thaw damage. The variable $\mathrm{X}$ is the $C O D_{\mathrm{m}}$ and the $\mathrm{Y}$ is the $A_{\mathrm{f}}^{\text {eff }}$. 


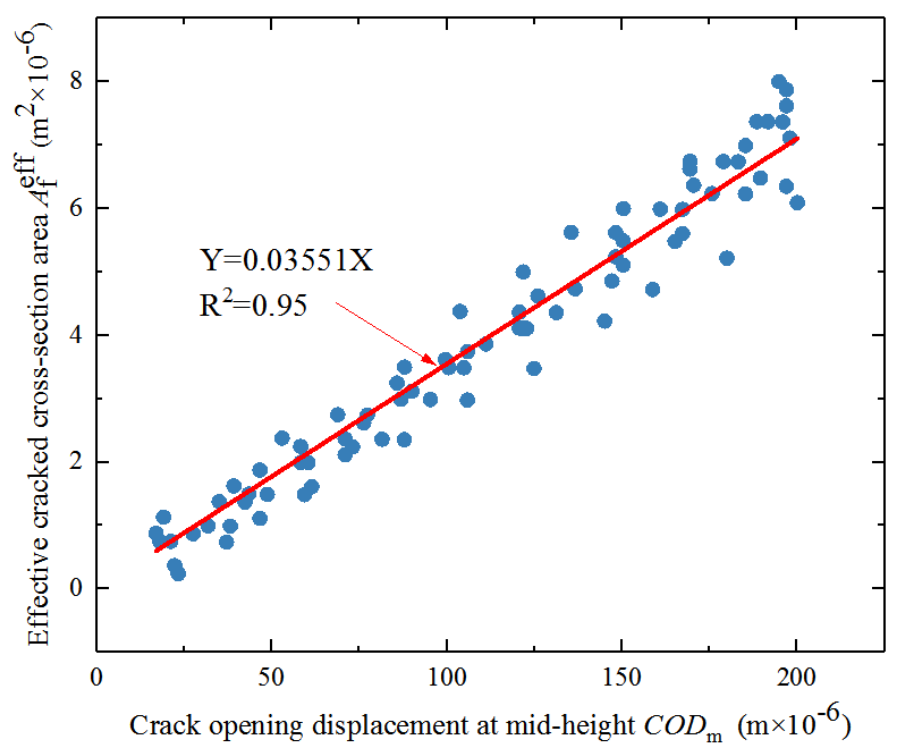

Fig. 5. Relationship between $C O D_{\mathrm{m}}$ and $A_{\mathrm{f}}^{\text {eff }}$ of a sample

200

Table 2

201 Fitted parameter $c$ of regression equation between $C O D_{\mathrm{m}}$ and $A_{\mathrm{f}}^{\text {eff }}$ of all samples

\begin{tabular}{llccc}
\hline \multirow{2}{*}{$R D M E$} & \multicolumn{4}{c}{ Fitted parameter $c$} \\
\cline { 2 - 4 } & $\mathrm{NC}$ & $\mathrm{SF} 20$ & $\mathrm{SF} 40$ & $\mathrm{SF60}$ \\
\hline $100 \%$ & 0.02906 & 0.03256 & 0.03551 & 0.04039 \\
& $\left(R^{2}=0.99\right)$ & $\left(R^{2}=0.99\right)$ & $\left(R^{2}=0.95\right)$ & $\left(R^{2}=0.98\right)$ \\
$90 \%$ & 0.02639 & 0.03269 & 0.04807 & 0.03521 \\
$75 \%$ & $\left(R^{2}=0.96\right)$ & $\left(R^{2}=0.99\right)$ & $\left(R^{2}=0.97\right)$ & $\left(R^{2}=0.96\right)$ \\
& 0.03242 & 0.05171 & 0.05896 & 0.04262 \\
$60 \%$ & $\left(R^{2}=0.99\right)$ & $\left(R^{2}=0.96\right)$ & $\left(R^{2}=0.97\right)$ & $\left(R^{2}=0.96\right)$ \\
& 0.03022 & 0.0223 & 0.03807 & 0.03936 \\
& $\left(R^{2}=0.97\right)$ & $\left(R^{2}=0.97\right)$ & $\left(R^{2}=0.96\right)$ & $\left(R^{2}=0.99\right)$ \\
\hline
\end{tabular}

For the permeability test under splitting tensile load, the vacuum permeability set-up was assembled with two vessels, a water pump, a vacuum pump, a sealed container and an electronic scale (Fig. 6). Before the permeability test, the processing of vacuuming and 
saturating water for specimens was carried out, and then the waterproof tape was applied to wrap the lateral surface of the specimens, silicon rings ( $3 \mathrm{~mm}$ thick) were interposed between vessels and faces of specimens. The water pump was employed to fill up the upstream vessel with water.

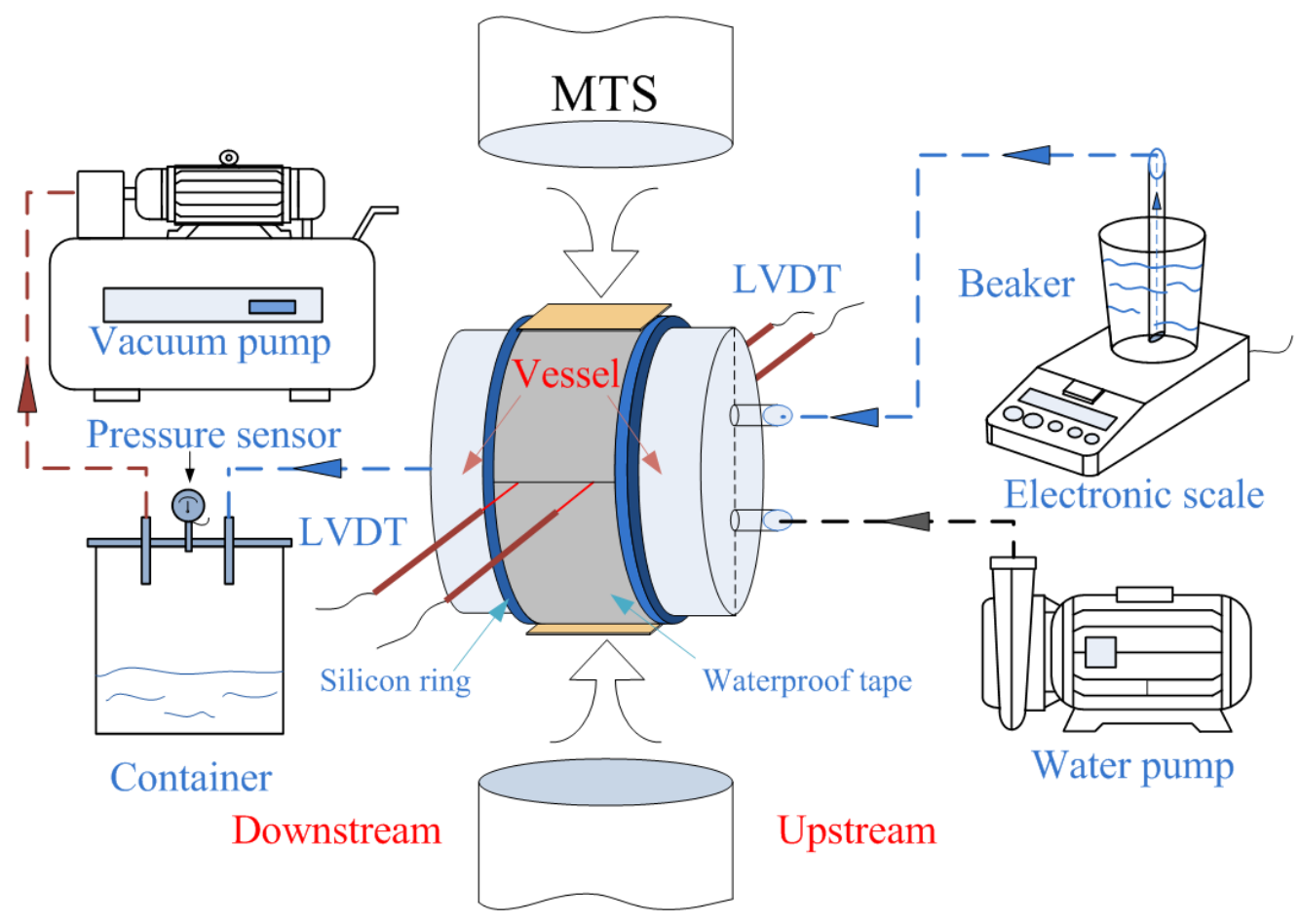

Fig. 6. Schematic view of vacuum permeability set-up

During the permeability test, an absolute pressure $p_{\mathrm{d}}$ between $10 \mathrm{kPa}$ and $12 \mathrm{kPa}$ was maintained by means of a vacuum pump. A pressure sensor was connected to the sealed container to measure the downstream pressure in real time and the constant atmospheric pressure $p_{\mathrm{u}}(100.8 \mathrm{kPa})$ was maintained on the upstream surface. The pressure drop $\left(\Delta p=p_{\mathrm{u}^{-}}\right.$ $p_{\mathrm{d}}$ ) between two surfaces of specimen was controlled in the range between $88.8 \mathrm{kPa}$ and 90.8 $\mathrm{kPa}$. 
electronic scale and used to calculate the water mass flow rate through specimens $Q(\mathrm{~kg} / \mathrm{s}) . Q$ included the water mass flow rate through crack $Q_{\mathrm{c}}(\mathrm{kg} / \mathrm{s})$ and the water mass flow rate through concrete matrix $Q_{\mathrm{m}}(\mathrm{kg} / \mathrm{s})$. Before splitting loading, the permeability test lasted about $3 \mathrm{~h}$ to achieve a steady-state of water flow through the intact concrete matrix and the steady-state of water flow could be applied to calculate $Q_{\mathrm{m}}$. Subsequently, $Q_{\mathrm{c}}$ can be calculated using Eq. $(5)^{[22]}$.

$$
Q_{\mathrm{c}}=Q-Q_{\mathrm{m}}
$$

\subsection{Analysis of crack permeability and effective crack width}

The permeability test was performed using a pressure gradient of about $1.8 \mathrm{MPa} / \mathrm{m}$. This resulted in a laminar flow with Reynolds numbers smaller than 100. Under the theory of laminar flow of incompressible Newtonian fluid, Darcy's law can be employed. For unidirectional permeability test, the crack permeability of concrete can be calculated by Eq. (6).

$$
\kappa=\frac{Q_{\mathrm{c}}}{A_{\mathrm{f}}^{\text {eff }}} \frac{\mu}{\rho}\left(\frac{\mathrm{V} p}{\mathrm{~V} x}\right)^{-1}=\frac{Q_{\mathrm{c}}}{\omega \cdot L} \frac{\mu}{\rho}\left(\frac{\mathrm{V} p}{\mathrm{~V} x}\right)^{-1}
$$

where $\kappa$ is the crack permeability of concrete, $\mathrm{m}^{2} ; \mu$ is the water dynamic viscosity, 0.001 $\mathrm{Pa} \cdot \mathrm{s} ; \rho$ is the density of water, $998 \mathrm{~kg} / \mathrm{m}^{3} ; \Delta p / \Delta x$ is the pressure gradient, $\mathrm{Pa} / \mathrm{m} . A_{\mathrm{f}}^{\text {eff }}$ is the effective cracked cross-section area of the specimen, $\mathrm{m}^{2} ; L$ is the mean crack length perpendicular to the direction of water flow on the upstream and downstream faces, $\mathrm{m} ; \omega$ is the effective crack width (see Fig. 7), m. 


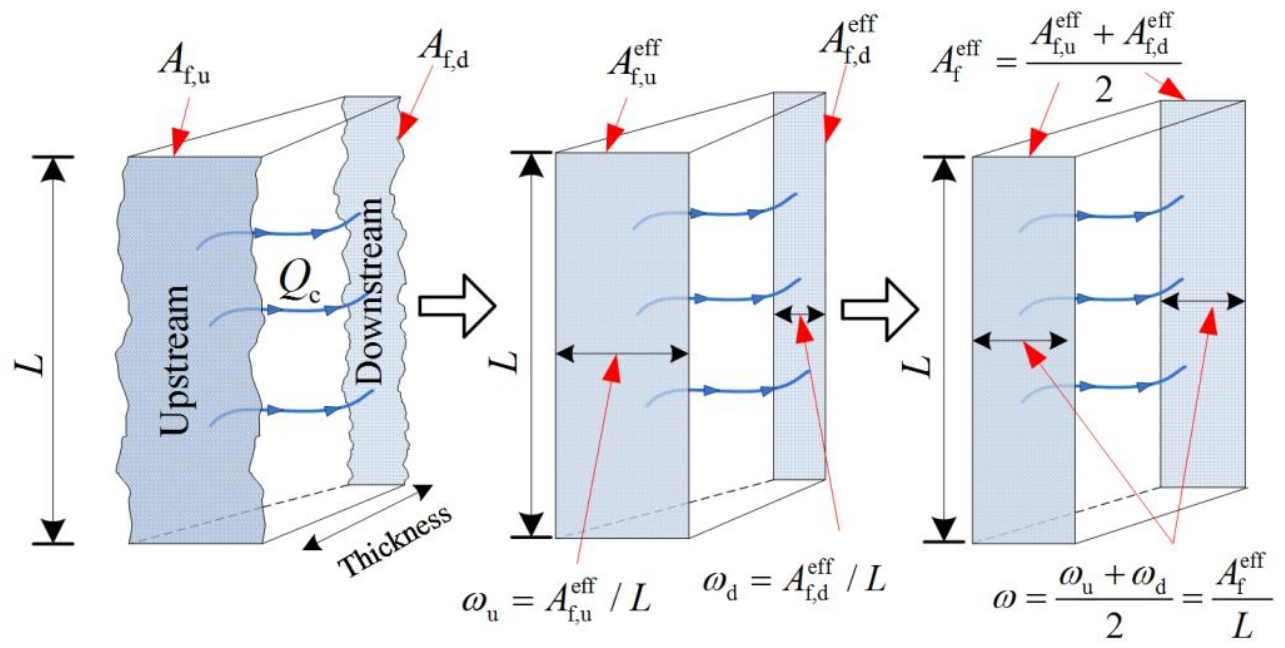

Fig. 7. Computational method of effective crack width ${ }^{[8]}$

The incompressible fluid flow through a single crack can be evaluated by the Poiseuille be identified as the function of $\omega$ (see Eq. (7)).

$$
\kappa_{\mathrm{PFM}}=\frac{\omega^{2}}{12}
$$

In fact, the surface of concrete cracks is rather rough and the width of opening crack is not uniform. The concrete mix, fiber types and fiber contents have important influences on the roughness of crack surface ${ }^{[11]}$. In order to estimate the crack permeability $(\kappa)$ of concrete, a modified factor $\xi^{[8,11,12,23]}$ has been employed to quantify the effect of the crack topography of different concrete samples on the crack permeability (Eq. (8)).

$$
\xi=\frac{\kappa}{\kappa_{\mathrm{PFM}}}
$$

Combining Eq. (7) and Eq. (8) results in:

$$
\kappa=\xi \cdot \frac{\omega^{2}}{12}
$$


After the splitting tensile test and permeability test, the specimens were split into two pieces along the $\operatorname{crack}^{[11]}$. The fibers on the crack surface were cut before scanning. Subsequently, the invented 3-D laser scanning equipment was used to gather the topographical information of the crack surface (Fig. 8). This equipment was a non-contact device which enables to obtain the coordinates of the points on the crack surface by the laser sensors. The laser sensors provided an accuracy of $7 \mu \mathrm{m}$. The vertical projection area of scanning region was $75 \mathrm{~mm} \times 35 \mathrm{~mm}$.

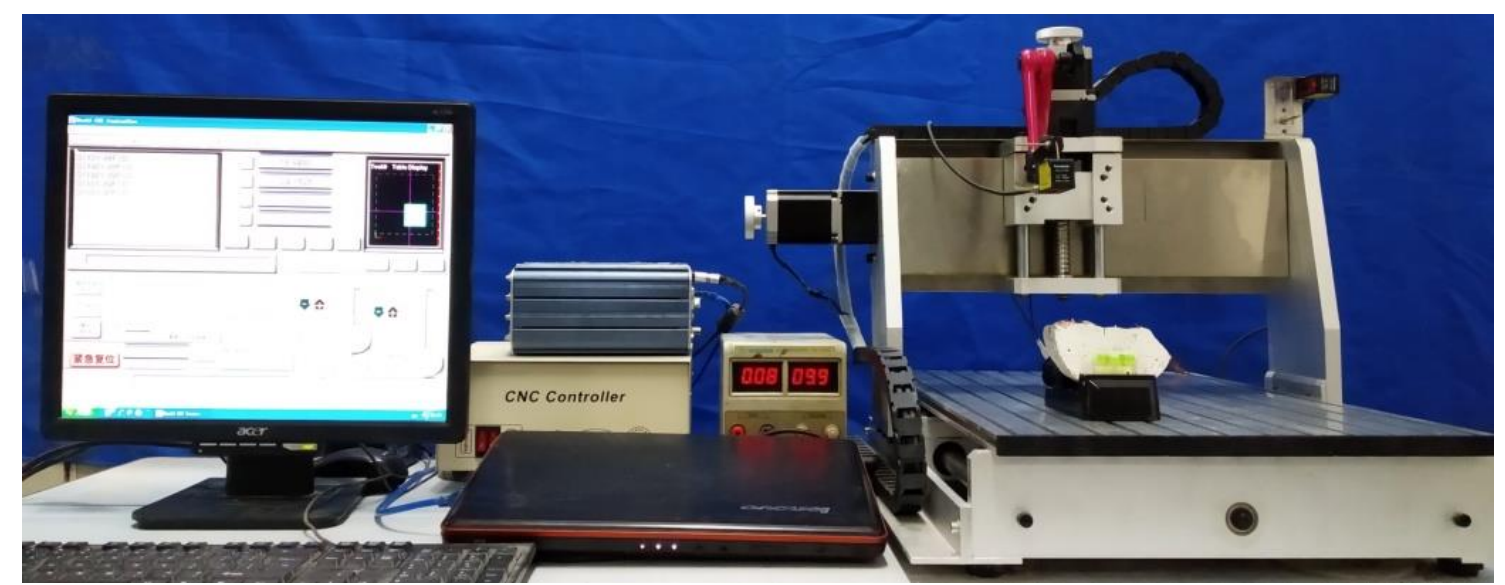

Fig. 8. Experimental set-up of the 3-D laser scanning equipment ${ }^{[11]}$

The roughness number ${ }^{[24-26]}(R N)$ can be extracted from the crack surface to accurately 273 estimate the roughness of the crack surface (Fig. 9). Fig. 9(a) shows the wireframe view ${ }^{[27]}$ of $^{2}$ 274 the reconstructed crack surface, and Fig. 9(b) shows the magnified view of one element in the 275 wireframe view. The $A_{o}$ is the vertical projection of the crack surface area $A_{s}$ on the horizontal $\mathrm{X}-\mathrm{Y}$ plane. The number of elements in crack surface area $A_{s}$ is $N$. The surface area $A_{i, j}$ of each

277 element is divided into two triangles, their surface areas $\left(A_{a}\right.$ and $\left.A_{b}\right)$ are calculated according to the Heron's formula. The $R N$ can be calculated by Eq. (10) and Eq. (11). 


$$
R N=\frac{A_{s}}{A_{\mathrm{o}}}
$$

$$
A_{s}=\sum_{i, j=1}^{N} A_{i, j}=\sum_{i, j=1}^{N}\left(A_{a}+A_{b}\right)
$$

where $A_{\mathrm{s}}$ is the crack surface area, $A_{o}$ is the projected area of crack surface.

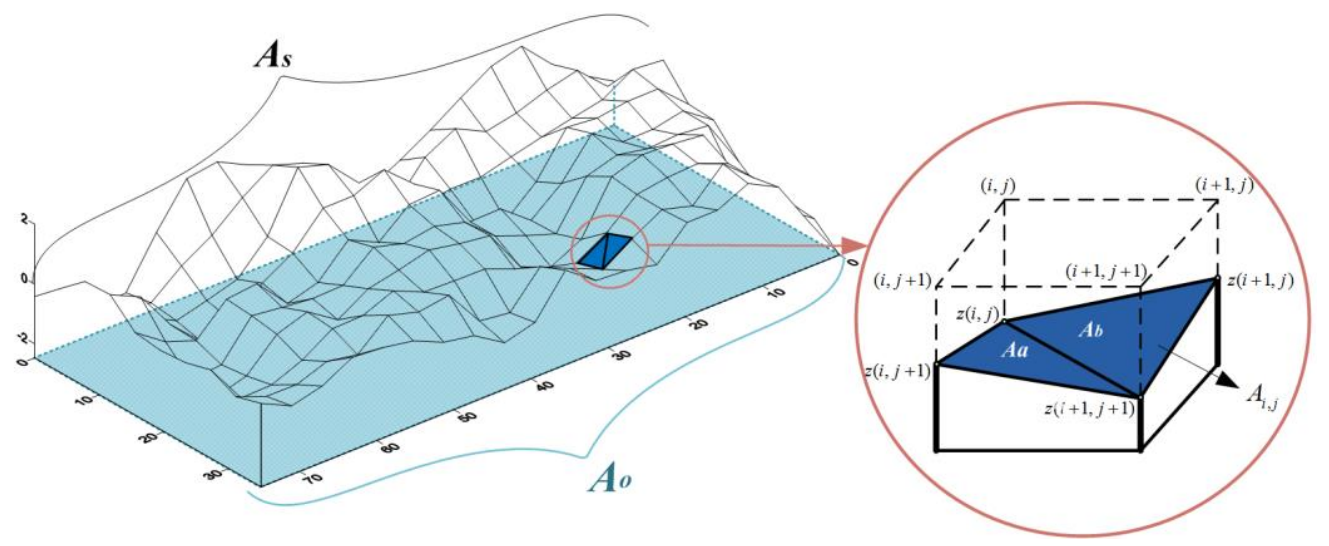

(a) Wireframe view of the reconstructed

(b) Magnified view of one element in crack surface; the wireframe view Fig. 9. Schematic view of crack surface topography

\section{Results and discussion}

3.1. Relative dynamic modulus of elasticity of SFRC after freeze-thaw cycles freeze-thaw cycles of different samples. 


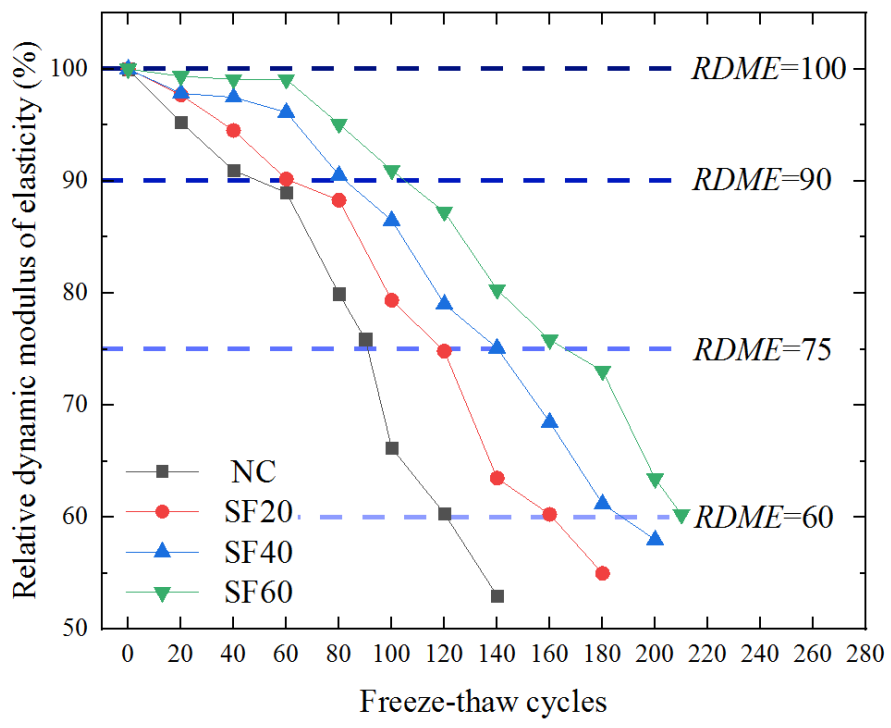

Fig. 10. Relationship between the $R D M E$ and the freeze-thaw cycles of different samples

From Fig. 10, it can be seen that when different samples are subjected to freeze-thaw cycles, the RDME of NC slopes down faster than those of SFRC specimens. Meanwhile, the $R D M E$ drop rate of SFRC specimens decreases with the increasing of steel fiber content.

The discussion above demonstrates that the steel fiber shows a significant effect on the freeze-thaw resistance of concrete. On the one hand, steel fiber enhances the freeze-thaw resistance by bridging cracks and reducing the crack width. On the other hand, the presence of steel fiber in the concrete increases the content of closed pores which can relieve the water freezing pressure and reduce the damage caused by freeze-thaw cycles ${ }^{[28-31]}$.

Fig. 11 shows the relationship between the effective crack width $\omega(0 \sim 300 \mu \mathrm{m})$ and the crack permeability for all samples with and without steel fiber in specific freeze-thaw damage levels (i.e. $R D M E=100 \%, 90 \%, 75 \%$ and $60 \%$ ). The crack permeability predicted by Poiseuille flow model $\kappa_{\mathrm{PFM}}$ is studied as reference (the curve in purple colour). The comparison of the crack permeability of different samples at different effective crack width is 
308

Table 3

315 Comparison of the crack permeability of different samples samples

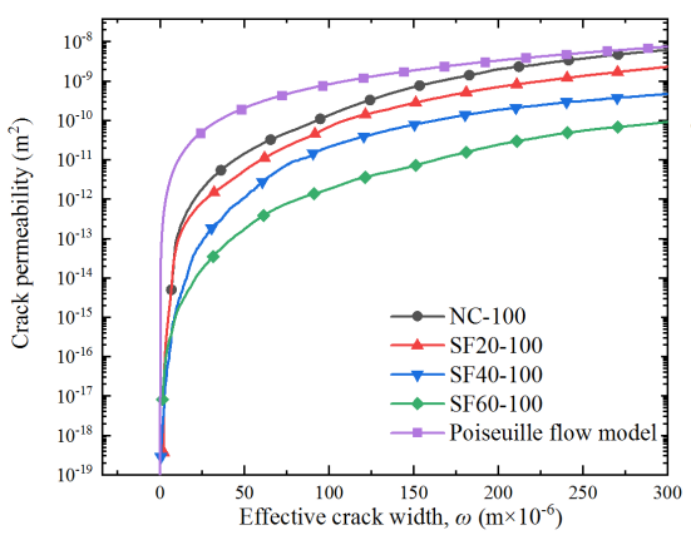

(a)

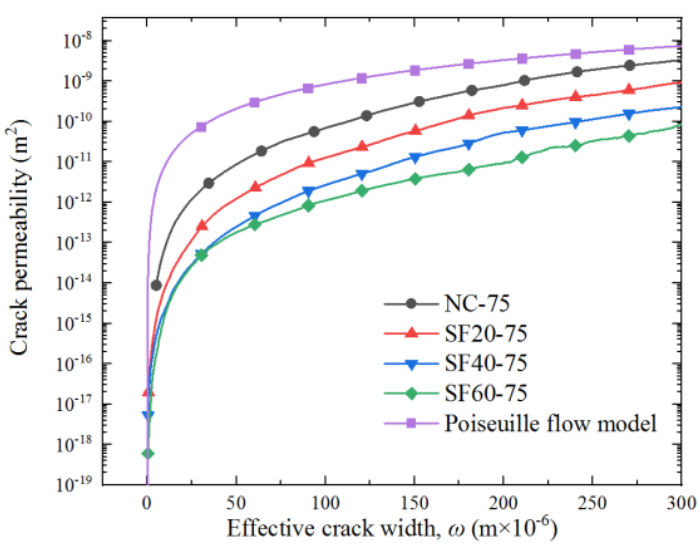

(c)

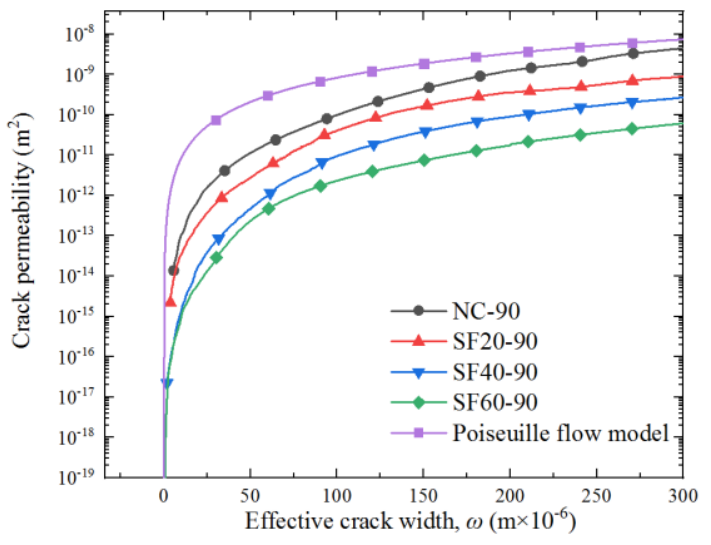

(b)

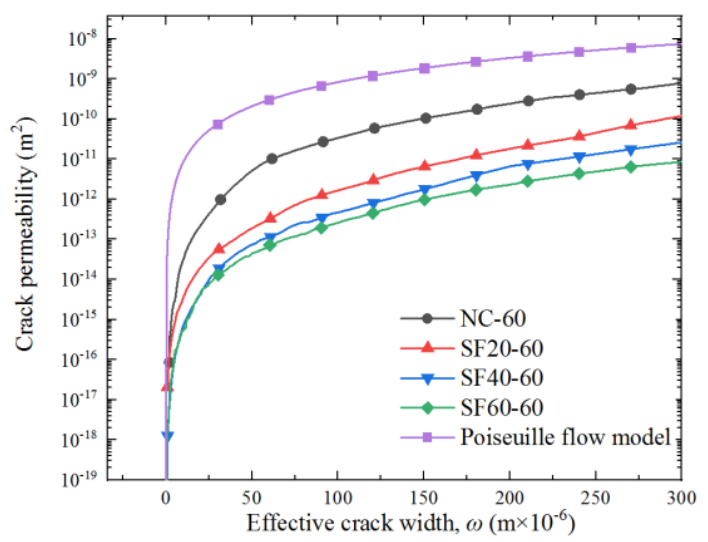

(d)

Fig. 11. Relationship between the crack permeability and the effective crack width of different

\begin{tabular}{|c|c|c|c|c|c|c|c|c|}
\hline $1 \mathrm{~m}^{2}$ & \multicolumn{4}{|c|}{$\omega=100 \mu \mathrm{m}$} & \multicolumn{4}{|c|}{$\omega=200 \mu \mathrm{m}$} \\
\hline & $\mathrm{NC}$ & SF20 & SF40 & SF60 & $\mathrm{NC}$ & SF20 & SF40 & SF60 \\
\hline $100 \%$ & $1.37 \times 10^{-10}$ & $6.97 \times 10^{-11}$ & $2.12 \times 10^{-11}$ & $2.06 \times 10^{-12}$ & $2.00 \times 10^{-9}$ & $7.11 \times 10^{-10}$ & $1.87 \times 10^{-10}$ & $2.44 \times 10^{-11}$ \\
\hline $90 \%$ & $9.91 \times 10^{-11}$ & $4.18 \times 10^{-11}$ & $9.52 \times 10^{-12}$ & $2.03 \times 10^{-12}$ & $1.25 \times 10^{-9}$ & $3.57 \times 10^{-10}$ & $8.97 \times 10^{-11}$ & $1.86 \times 10^{-11}$ \\
\hline
\end{tabular}




\begin{tabular}{lllllllll}
$75 \%$ & $6.93 \times 10^{-11}$ & $1.28 \times 10^{-11}$ & $2.68 \times 10^{-12}$ & $1.10 \times 10^{-12}$ & $8.00 \times 10^{-10}$ & $2.19 \times 10^{-10}$ & $5.31 \times 10^{-11}$ & $9.29 \times 10^{-12}$ \\
$60 \%$ & $3.38 \times 10^{-11}$ & $1.67 \times 10^{-12}$ & $4.68 \times 10^{-13}$ & $2.60 \times 10^{-13}$ & $2.43 \times 10^{-10}$ & $1.82 \times 10^{-11}$ & $6.59 \times 10^{-12}$ & $2.31 \times 10^{-12}$ \\
\hline
\end{tabular}

317 From Fig. 11 and Table 3, it can be seen that

318 i) With the increasing of effective crack width, the crack permeability of all samples 319 increases monotonically. For instance, for NC-100, when the effective crack width increases 320 from $100 \mu \mathrm{m}$ to $200 \mu \mathrm{m}$, the crack permeability is enlarged from $1.37 \times 10^{-10} \mathrm{~m}^{2}$ to $2.00 \times 10^{-9}$ $321 \mathrm{~m}^{2}$. samples gradually decreases for the same crack width, e.g. for SF20, when the effective crack width is $100 \mu \mathrm{m}$, compared with the SF20-100 specimen, the crack permeability of SF20-90, SF20-75 and SF20-60 decrease about 40.0\%, 81.6\% and 97.6\%, respectively.

iii) The curves of crack permeability of SFRC are lower than that of NC and the crack permeability decreases with the increasing of fiber content for all freeze-thaw damage levels.

iv) The curves of crack permeability of all samples are similar to the curve predicted by the Poiseuille flow model, but the crack permeability of different crack width is lower than the value predicted by the Poiseuille flow model.

From the discussion above, it can be summarized that the predicted curve according to the Poiseuille flow model is much higher than the experimental results of various specimens, especially higher than those of SFRC samples.

\subsection{Relationship between effective crack width and modified factor $\xi$}

The modified factor $\xi$ is equal to the ratio between $\kappa_{\mathrm{PFM}}$ and $\kappa$ (Eq. (8)). The relationship between modified factor $\xi$ and effective crack width is shown in Fig. 12. The comparison of the modified factor $\xi$ of different samples at different effective crack width is shown in Table 4. 


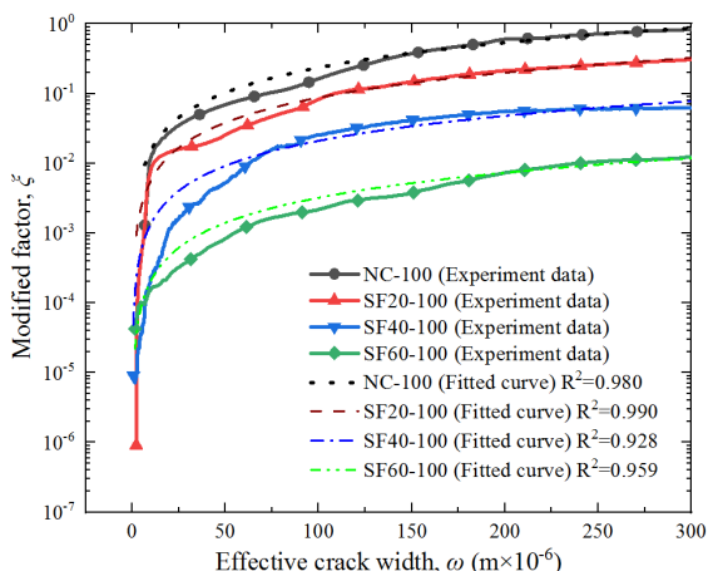

(a)

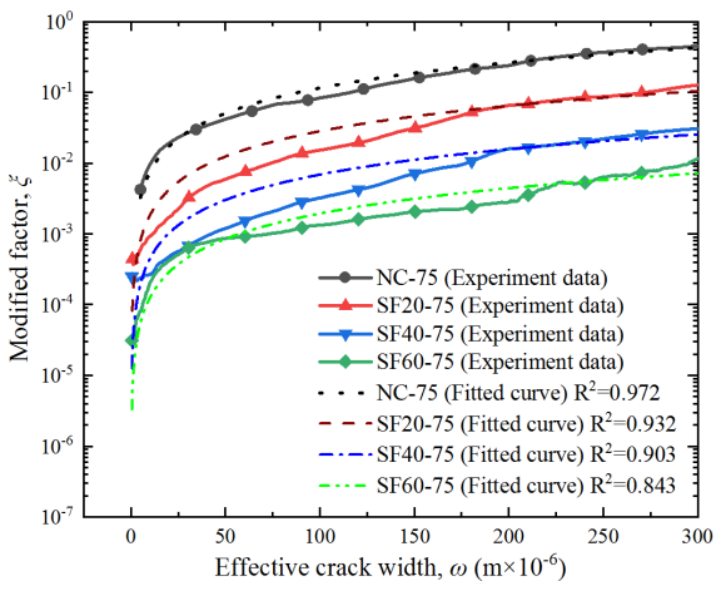

(c)

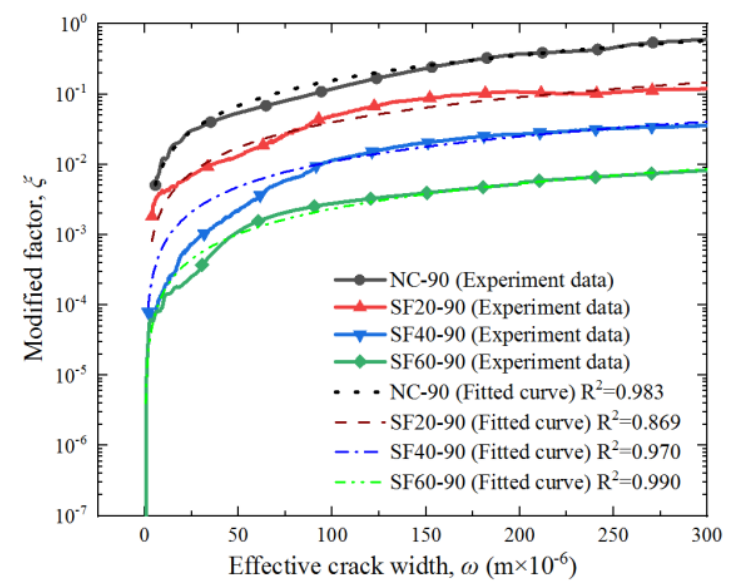

(b)

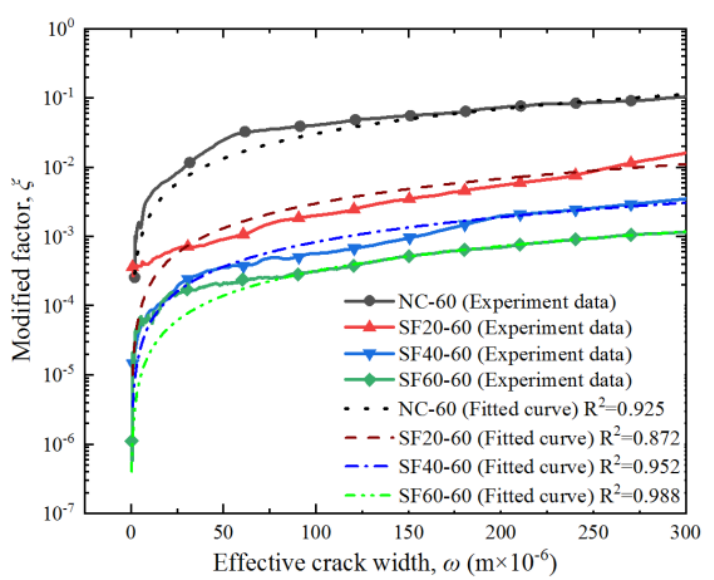

(d)

343 Fig. 12. Relationship between the modified factor $\xi$ and the effective crack width for different samples

\section{Table 4}

346 Comparison of the modified factor $\xi$ of different samples

\begin{tabular}{|c|c|c|c|c|c|c|c|c|}
\hline & \multicolumn{4}{|c|}{$\omega=100 \mu \mathrm{m}$} & \multicolumn{4}{|c|}{$\omega=200 \mu \mathrm{m}$} \\
\hline$R D M E$ & $\mathrm{NC}$ & SF20 & SF40 & SF60 & $\mathrm{NC}$ & SF20 & SF40 & SF60 \\
\hline $100 \%$ & $1.64 \times 10^{-1}$ & $8.36 \times 10^{-2}$ & $2.54 \times 10^{-2}$ & $2.47 \times 10^{-3}$ & $6.00 \times 10^{-1}$ & $2.13 \times 10^{-1}$ & $5.61 \times 10^{-2}$ & $7.32 \times 10^{-3}$ \\
\hline $90 \%$ & $1.19 \times 10^{-1}$ & $5.02 \times 10^{-2}$ & $1.14 \times 10^{-2}$ & $2.43 \times 10^{-3}$ & $3.75 \times 10^{-1}$ & $1.07 \times 10^{-1}$ & $2.69 \times 10^{-2}$ & $5.58 \times 10^{-3}$ \\
\hline
\end{tabular}




\begin{tabular}{lllllllll}
$75 \%$ & $8.32 \times 10^{-2}$ & $1.54 \times 10^{-2}$ & $3.22 \times 10^{-3}$ & $1.32 \times 10^{-3}$ & $2.40 \times 10^{-1}$ & $6.57 \times 10^{-2}$ & $1.59 \times 10^{-2}$ & $2.79 \times 10^{-3}$ \\
$60 \%$ & $4.06 \times 10^{-2}$ & $2.00 \times 10^{-3}$ & $5.62 \times 10^{-4}$ & $3.12 \times 10^{-4}$ & $7.29 \times 10^{-2}$ & $5.46 \times 10^{-3}$ & $1.98 \times 10^{-3}$ & $6.93 \times 10^{-4}$ \\
\hline
\end{tabular}

348 From Fig. 12 and Table 4, it can be seen that

349 i) With the increasing of steel fiber content, the modified factor $\xi$ of samples decreases 350 for the same crack width.

ii) With the increment of the effective crack width, the modified factor $\xi$ of all samples gradually increases.

iii) With the increasing of freeze-thaw damage level, the modified factor $\xi$ of samples decreases for the same crack width.

With the increasing of the crack opening, the crack permeability of all samples approaches to that of the value predicted by the Poiseuille flow model, and the trend is consistent with the reported data ${ }^{[8]}$. Meanwhile, the crack permeability is proportional to the square of the crack width in accordance with the Poiseuille flow model (see Eq. (7) and Eq. (9)). It means that with the increasing of effective crack width, the crack permeability indicates a remarkable increase. The roughness of crack surface is constant after crack opening, and it has no incremental effect on the crack permeability with the crack widening. According to the experiment data, the addition of steel fiber can effectively decrease the increase rate of crack permeability with the crack opening. This phenomenon becomes obviously with the increasing of freeze-thaw damage level.

The modified factor $\xi$ was often considered as a constant to quantify the trend of crack permeability in previous investigations ${ }^{[11,12,23]}$. However, the crack geometry changes with the increasing of crack opening under splitting tensile loading, so the $\xi$ is a variable with different 
crack opening and not suitable to evaluate the permeability of cracked concrete. Rastiello et al. ${ }^{[8]}$ indicated that the $\xi$ could be estimated by a function of the crack opening as follows:

$$
\xi=\xi(\omega)=\alpha \omega^{\beta}
$$

where $\beta$ is a constant factor $\left(\beta=1.19^{[8]}\right) ; \omega$ is the effective crack width in the range between 0 $\mu \mathrm{m}$ and $300 \mu \mathrm{m} ; \alpha$ is the material permeability parameter, which varies from sample to sample.

Replace $\xi$ of Eq. (12) in Eq. (9) resulting the following equation:

$$
\kappa=\alpha \cdot \frac{\omega^{\beta+2}}{12}
$$

In Eq. (13), when the crack width is fixed, the crack permeability $(\kappa)$ of concrete is directly proportional to the material permeability parameter $\alpha$. In other words, the material permeability parameter $\alpha$ in Eq. (13) can be applied to quantify the crack permeability of different samples. Based on the experimental data, the fitted curves of different samples according to Eq. (12) are illustrated in Fig. 12. The correlation coefficient $R^{2}$ of all fitted curves is more than 0.84 . Namely, the relationship between the effective crack width and the modified factor $\xi$ of all specimens corresponds well with the fitted curves. The average values of $\alpha$ for different samples are illustrated in Table 5 and Fig. 13. The relationship of material permeability parameter $\alpha$ - steel fiber content - RDME is illustrated and analyzed by two different comparison methods in Fig. 13(a) and Fig. 13(b). As mentioned in Subsection 2.3, the $R D M E$ value is the same as the freeze-thaw damage level.

\section{Table 5}

Fitted parameters of regression equation

\begin{tabular}{llllll}
\hline \multirow{2}{*}{$R D M E$} & $\beta$ & \multicolumn{5}{c}{$\alpha$} \\
\cline { 3 - 6 } & & $\mathrm{NC}$ & $\mathrm{SF} 20$ & $\mathrm{SF} 40$ & $\mathrm{SF60}$ \\
& & & & & \\
\hline
\end{tabular}




\begin{tabular}{ccccc}
\hline $100 \%$ & 13536.04 & 5025.68 & 1209.13 & 184.60 \\
& $(C \mathrm{v}=6.1 \%)$ & $(C \mathrm{v}=8.9 \%)$ & $(C \mathrm{v}=5.4 \%)$ & $(C \mathrm{v}=7.6 \%)$ \\
$90 \%$ & 9020.98 & 2290.99 & 632.11 & 134.66 \\
& $1.19^{[8]}$ & $(C \mathrm{v}=3.7 \%)$ & $(C \mathrm{v}=8.3 \%)$ & $(C \mathrm{v}=10.3 \%)$ \\
$75 \%$ & 6620.48 & 1623.07 & 395.82 & 111.36 \\
& $(C \mathrm{v}=9.7 \%)$ & $(C \mathrm{v}=5.2 \%)$ & $(C \mathrm{v}=8.3 \%)$ & $(\mathrm{Cv}=6.5 \%)$ \\
$60 \%$ & 1750.39 & 171.41 & 47.64 & 18.23 \\
& $(C \mathrm{v}=7.2 \%)$ & $(C \mathrm{v}=6.4 \%)$ & $(C \mathrm{v}=9.5 \%)$ & $(C \mathrm{v}=9.1 \%)$ \\
\hline
\end{tabular}

392

393

394

395

396

397

398

399

400

401

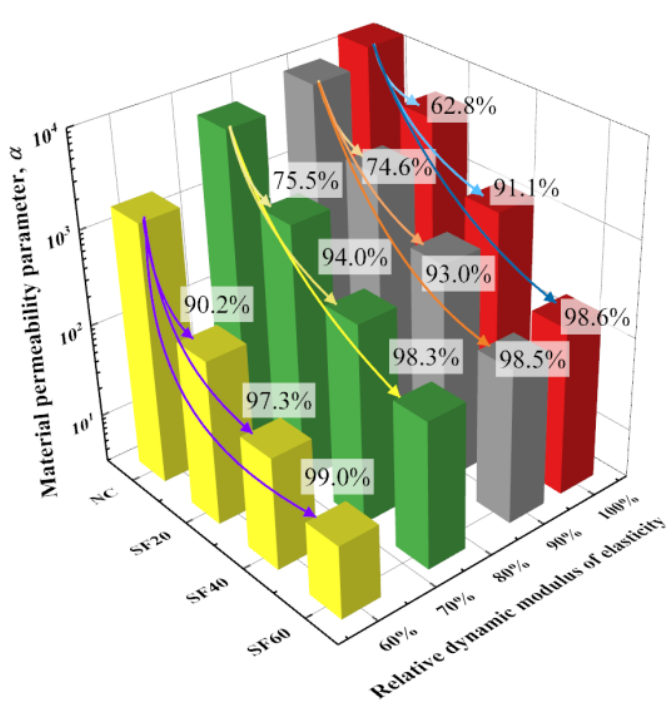

(a)

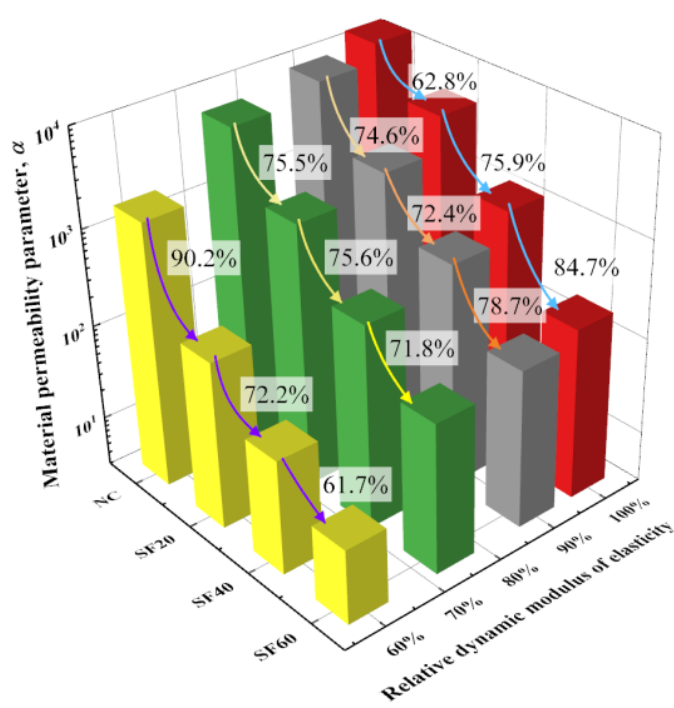

(b)

Fig. 13. Bar charts of material permeability parameter $\alpha$

Fig. 13 shows the bar chart of material permeability parameter $\alpha$ of all samples, which declines with the increasing of steel fiber contents. The samples without freeze-thaw damage $(R D M E=100 \%$, in red columns) are adopted as the reference specimens. From Fig. 13(a), the following points can be observed:

i) The $\alpha$ value decreases for all freeze-thaw damage levels with the increasing of fiber 
contents. For instance, the $\alpha$ values of NC-90, SF20-90, SF40-90 and SF60-90 are 9020.98, 2290.99, 632.11 and 134.66. Compared with the NC-90 specimen, the $\alpha$ values of SF20-90, SF40-90 and SF60-90 decrease by $74.6 \%, 93.0 \%$ and $98.5 \%$, respectively.

ii) When freeze-thaw damage level of samples increases, the reduction of the $\alpha$ value becomes obvious with the increasing of fiber contents. For instance, when the RDME (or freeze-thaw damage level) reaches $75 \%$, compared with the NC-75 specimen, the $\alpha$ values of SF20-75, SF40-75 and SF60-75 decrease by $75.5 \%, 94.0 \%$ and $98.3 \%$, respectively. When the RDME reaches $60 \%$, compared with the NC-60 specimen, the $\alpha$ values of SF20-60, SF40-60 and SF60-60 decrease by 90.2\%, 97.3\% and 99.0\%, respectively.

From Fig. 13(b), the points as follows can be seen:

i) Compared with the NC specimen, the $\alpha$ of SF20 decreases by $62.9 \%, 74.6 \%, 75.5 \%$ and $90.2 \%$ in specific freeze-thaw damage levels $(R D M E=100 \%, 90 \%, 75 \%$ and $60 \%)$, respectively. The decrease rate increases from $62.9 \%$ up to $90.2 \%$ with the increasing of freeze-thaw damage.

ii) Compared with the SF20 specimen, the $\alpha$ of SF40 decreases by $75.9 \%, 72.4 \%, 75.6 \%$ and $72.2 \%$ in specific freeze-thaw damage levels $(R D M E=100 \%, 90 \%, 75 \%$ and $60 \%)$, respectively. The decrease rate keeps about $74 \%$ with increment of freeze-thaw damage level.

iii) Compared with the SF40 specimen, the $\alpha$ of SF60 decreases by $84.7 \%, 78.7 \%, 71.9 \%$ and $61.7 \%$ in specific freeze-thaw damage levels $(R D M E=100 \%, 90 \%, 75 \%$ and $60 \%)$, respectively. With increment of freeze-thaw damage level, the decrease rate decreases from $84.7 \%$ down to $61.7 \%$.

Because the material permeability parameter $\alpha$ can be applied to quantify the crack permeability (Eq. (13)). The discussion above demonstrates that with increment of freeze-thaw damage level, the crack permeability of SF20 decreases significantly. But with the increasing of steel fiber content (from $20 \mathrm{~kg} / \mathrm{m}^{3}$ to $40 \mathrm{~kg} / \mathrm{m}^{3}$ and $60 \mathrm{~kg} / \mathrm{m}^{3}$ ), the effect of the additional steel fiber on reducing the crack permeability declines gradually with the increasing of freeze-thaw damage. Therefore, for the concrete without freeze-thaw damage 
(red columns), with the increasing of steel fiber content, the crack permeability decreases gradually. However, regarding the cost-efficiency, we notice that the concrete with low steel fiber content (SF20) on reducing crack permeability is higher than that of concrete with high steel fiber content (SF40 and SF60) for the concrete subjected to freeze-thaw damage.

In order to accurately quantify the effect of the presence of steel fiber on the crack surface topography of concrete with different freeze-thaw damage levels, the topographical information of crack surface was estimated by the invented 3-D laser scanning equipment and the crack surface of concrete was reconstructed in accordance with topographical information of the surface. Fig. 14 demonstrates the reconstruction views of crack surface of different samples. The roughness number $(R N)$ of crack surface of all specimens is shown in Table 6 .

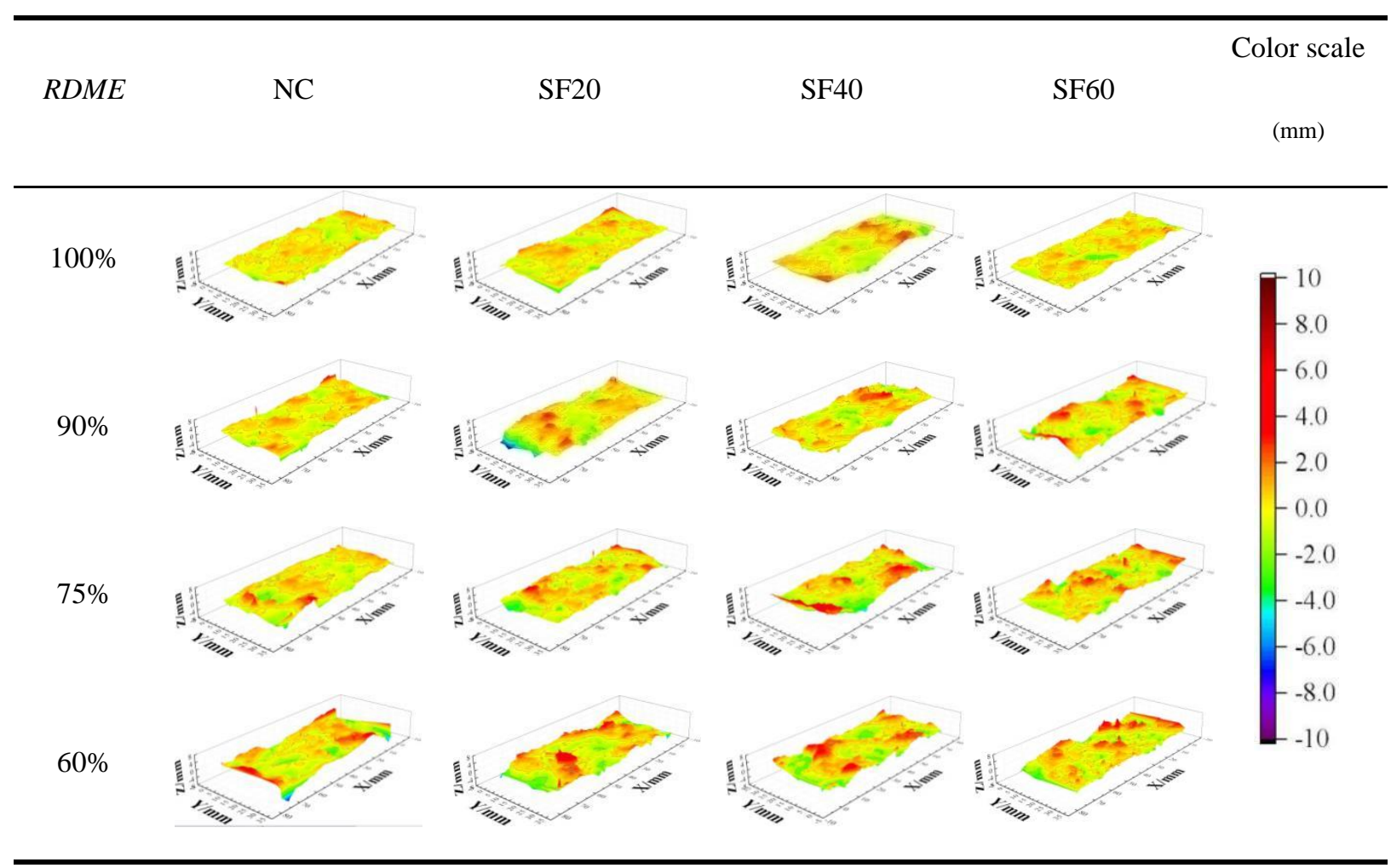


Analyses of roughness number of crack surface

\begin{tabular}{|c|c|c|c|c|}
\hline \multirow{2}{*}{$R D M E$} & \multicolumn{4}{|c|}{ Roughness number of crack surface $(R N)$} \\
\hline & $\mathrm{NC}$ & SF20 & SF40 & SF60 \\
\hline $100 \%$ & $\begin{array}{c}1.138 \\
(C \mathrm{v}=1.5 \%)\end{array}$ & $\begin{array}{c}1.216 \\
(\mathrm{Cv}=2.7 \%)\end{array}$ & $\begin{array}{c}1.319 \\
(C \mathrm{v}=3.4 \%)\end{array}$ & $\begin{array}{c}1.466 \\
(C \mathrm{v}=2.9 \%)\end{array}$ \\
\hline $90 \%$ & $\begin{array}{c}1.280 \\
(C \mathrm{v}=3.8 \%)\end{array}$ & $\begin{array}{c}1.351 \\
(\mathrm{Cv}=2.8 \%)\end{array}$ & $\begin{array}{c}1.395 \\
(\mathrm{Cv}=1.7 \%)\end{array}$ & $\begin{array}{c}1.510 \\
(\mathrm{Cv}=1.7 \%)\end{array}$ \\
\hline $75 \%$ & $\begin{array}{c}1.318 \\
(C \mathrm{v}=2.3 \%)\end{array}$ & $\begin{array}{c}1.459 \\
(C \mathrm{v}=2.3 \%)\end{array}$ & $\begin{array}{c}1.529 \\
(C \mathrm{v}=2.9 \%)\end{array}$ & $\begin{array}{c}1.680 \\
(C \mathrm{v}=2.3 \%)\end{array}$ \\
\hline $60 \%$ & $\begin{array}{c}1.366 \\
(C \mathrm{v}=2.7 \%)\end{array}$ & $\begin{array}{c}1.669 \\
(C \mathrm{v}=3.8 \%)\end{array}$ & $\begin{array}{c}1.692 \\
(C \mathrm{v}=1.5 \%)\end{array}$ & $\begin{array}{c}1.838 \\
(C \mathrm{v}=5.6 \%)\end{array}$ \\
\hline
\end{tabular}

From Fig. 14 and Table 6, it can be seen that the coefficient of variations $(\mathrm{Cv})$ of $R N$ values of all samples are very small (less than 5.6\%). For all freeze-thaw damage levels, the $R N$ of crack surface of FRC is higher than that of $\mathrm{NC}$, and the concrete crack surface becomes rough with the increasing of steel fiber content. Meanwhile, when the steel fiber content of specimens (include NC) is the same, the $R N$ of crack surface increases with the increasing of freeze-thaw damage level. The phenomenon above demonstrates that the presence of both steel fiber and the freeze-thaw damage leads to change the crack surface topography and improves the roughness of concrete crack surface.

Several investigations ${ }^{[11,17,32]}$ have demonstrated that the steel fiber in SFRC play a significant role on the crack trajectory and surface roughness. The reason is that the fibers, aggregates and paste of FRC form some "colonies" (Fig. 15), which may exhibit higher local tensile strength than that of aggregates and paste without steel fiber. It leads to that the crack can be prevented to propagate into the "colonies" and changed the trajectory path toward the interval of "colonies". It is known that the roughness of crack surface gradually increases with 
the increasing of aggregate size for the plain concrete ${ }^{[33]}$. For SFRC, the size of "colonies" is larger than that of aggregates, so the "colonies" of SFRC may cause a rougher crack surface than that caused by aggregates. With the increasing of fiber dosage, the "colonies" in SFRC matrix expands, which leads to an increment of the roughness of the crack surface. In addition, with the increasing of freeze-thaw damage of concrete with a given fiber content, the mechanical strength of concrete declines gradually. As the result, the specimen displays a less brittle failure and the degree of heterogeneity of concrete increases ${ }^{[34]}$. The crack propagation easily enters into the interval zone of aggregates/colonies rather than penetrating through aggregates/colonies, which leads to the increment of roughness of the crack surfaces ${ }^{[35,36]}$.

Crack surface is rough meaning its actual area is larger than the vertical projection area of the crack $^{[12]}$. The irregularity of crack surfaces increases the tortuosity of the water flow trajectory ${ }^{[37]}$, and at the same time the presence of flow barriers in cracks creates the additional pressure gradients along the flow path, which cause an increase in the head $\operatorname{losses}^{[38]}$. Therefore, the presence of steel fiber and the freeze-thaw damage improves the roughness of concrete crack surface and reduces the crack permeability.

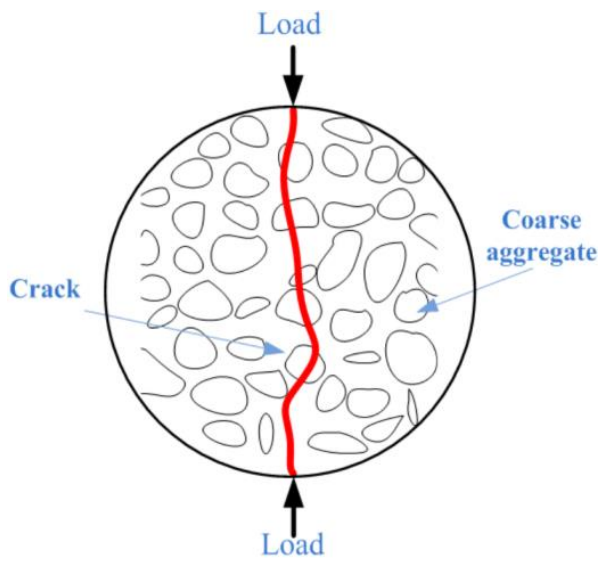

(a) Plain concrete

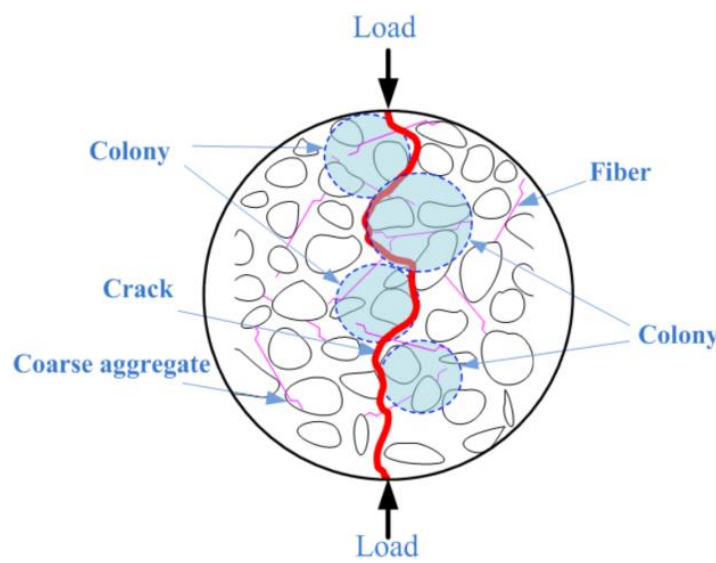

(b) Fiber reinforced concrete

Fig. 15. Schematic view of the crack propagation 
Based on the discussion in Subsection 3.4 and 3.5, it can be seen that with the increment

481

482

483

484

485

486

487

488 of crack surface roughness, the crack permeability gradually decreases. In order to quantify the relationship between crack surface topography and crack permeability, the crack permeability and topography of crack surface were converted to be explained by material permeability parameter $\alpha$ and roughness number $(R N)$ of crack surface, respectively. The $R N$ of crack surface was further correlated to the material permeability parameter $\alpha$, as shown in Fig. 16.

7

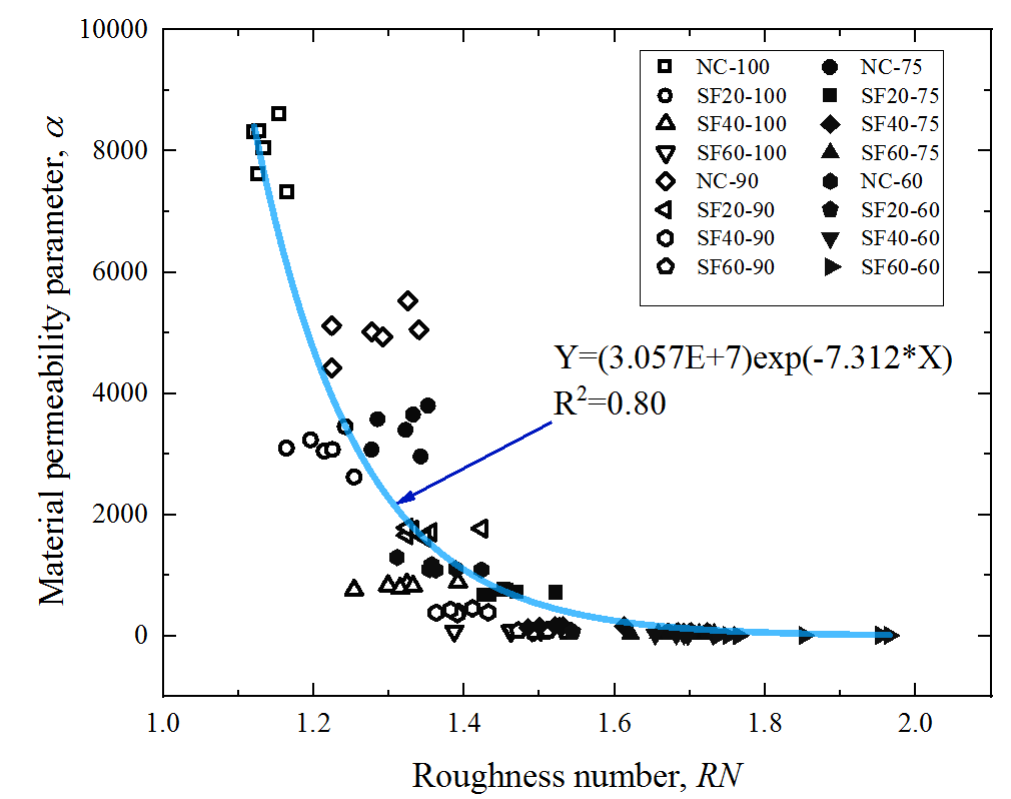

Fig. 16. Relationship of material permeability parameter $\alpha$ and crack surface roughness number

$$
\mathrm{Y}=m \cdot \exp (n \cdot \mathrm{X})
$$


where $m$ and $n$ are the parameters fitted corresponding to the experiment, the variable $\mathrm{X}$ is the $R N$ of crack surface and the $\mathrm{Y}$ is the material permeability parameter $\alpha$.

The discussion above demonstrates that the material permeability parameter $\alpha$ presents an exponential decrease with increment of $R N$. A similar phenomenon was confirmed by the published data ${ }^{[11]}$, this indicates the general applicability of Eq. (14).

It is known that compared with the permeability test, analysis of crack surface topography by means of the invented 3-D laser scanning equipment is simply, accurate and efficient $^{[17]}$. The function between material permeability parameter $\alpha$ and $R N$ of crack surface can be considered as a tool to estimate the crack permeability quickly by crack surface topography of concrete. The experimental result provides the theoretical support of future study of relationship between the durability and the crack surface topography of concrete.

\section{Conclusions}

From the research results, the following conclusions can be drawn:

1. The invented 3-D laser scanning equipment is able to acquire the topographical information and reconstruct the crack surface. The vacuum permeability set-up is capable to monitor the sequential water flow through the concrete crack and evaluate the crack permeability of concrete with the crack widening.

2. The crack permeability of concrete $\kappa$ is less than the value predicted by the Poiseuille flow model $\kappa_{\mathrm{PFM}}$. With the increasing of effective crack width, the difference between $\kappa$ and $\kappa_{\mathrm{PFM}}$ decreases gradually.

3. The presence of both steel fiber and the freeze-thaw damage enhances the roughness of concrete crack surface and reduces the crack permeability of concrete with different crack width $(0 \sim 300 \mu \mathrm{m})$. 
4. The exponent function established in this work fits well with the relationship between

521 the material permeability parameter $\alpha$ and the roughness number $(R N)$ of crack surface. Such

522 relationship can be employed to estimate quickly the crack permeability.

\section{Nomenclature}

RDME : relative dynamic modulus of elasticity;

NC : $\quad$ plain concrete without any reinforcement;

SF20 : $\quad$ steel fiber reinforced concrete with fiber dosage of $20 \mathrm{~kg} / \mathrm{m}^{3}$;

SF40 : $\quad$ steel fiber reinforced concrete with fiber dosage of $40 \mathrm{~kg} / \mathrm{m}^{3}$;

SF60 : $\quad$ steel fiber reinforced concrete with fiber dosage of $60 \mathrm{~kg} / \mathrm{m}^{3}$;

PFM : $\quad$ Poiseuille flow model;

$R N$ : $\quad$ roughness number

$C O D_{\mathrm{m}}$ : $\quad$ crack opening displacement at the mid height of the samples;

$A_{\mathrm{f}}^{\text {eff }}: \quad$ effective cracked cross-section area;

$\xi$ : $\quad$ modified factor of the Poiseuille flow model;

$Q: \quad$ water mass flow rate through specimens;

$Q_{\text {c }} \quad \quad \quad$ water mass flow rate through crack;

$Q_{\mathrm{m}}: \quad \quad$ water mass flow rate through concrete matrix.

\section{Acknowledgments}


530 [1] J. Zhang, V.C. Li, Monotonic and fatigue performance in bending of fiber-reinforced 531 engineered cementitious composite in overlay system, Cem. Concr. Res. 32 (2002) $532 \quad 415-423$.

533

[2] J. Bao, S. Xue, P. Zhang, Z. Dai, Y. Cui, Coupled effects of sustained compressive loading and freeze-thaw cycles on water penetration into concrete, Struct. Concr. (2020) 1-11.

[3] P.K. Mehta, P.J.M. Monteiro, Concrete: Microstructure Properties and Materials, Prentice-Hall, (2013).

[4] L. Wang, L. Chen, D.C.W. Tsang, H.W. Kua, J. Yang, Y.S. Ok, S. Ding, D. Hou and C.S. Poon, The roles of biochar as green admixture for sediment-based construction products, Cem. Concr. Compos. 104 (2019) 103348.

[5] L. Wang, L. Chen, J.L. Provis, D.C.W. Tsang andC.S. Poon, Accelerated carbonation of reactive $\mathrm{MgO}$ and Portland cement blends under flowing $\mathrm{CO} 2$ gas, Cem. Concr. Compos. $106(2020) 103489$.

[6] K. Wang, D.C. Jansen, S.P. Shah, A.F. Karr, Permeability study of cracked concrete, Cem. Concr. Res. 27 (1997) 381-393.

[7] C. Aldea, S. Shah, A. Karr, Permeability of cracked concrete, Mater. Struct. 32 (1999) 370-376.

[8] G. Rastiello, C. Boulay, P.S. Dal, J.L. Tailhan, P. Rossi, Real-time water permeability evolution of a localized crack in concrete under loading, Cem. Concr. Res. 56 (2014) 20-28.

[9] J. Rapoport, C. Aldea, S.P. Shah, B. Ankenman, A. Karr, Permeability of Cracked Steel Fiber-Reinforced Concrete, J. Mater. Civil Eng. 14 (2002) 355-358.

[10] Fib Bulletin 52, Structural concrete- textbook on behavior, design and performance, Vol. 2, Document Competence Center Siegmar Kastl e.K, (2010).

[11] Y. Ding, D. Li, Y. Zhang, Quantitative analysis of macro steel fiber influence on crack 
556 [12] A. Akhavan, S. Shafaatian, F. Rajabipour, Quantifying the effects of crack width, tortuosity, and roughness on water permeability of cracked mortars, Cem. Concr. Res. 42 (2012) 313-320.

559

[13] V. Mechtcherine, M. Lieboldt, Permeation of water and gases through cracked textile reinforced concrete, Cem. Concr. Compos. 33 (2011) 725-734.

[14] P. Zhu, S. Brunner, S. Zhao, M. Griffa, A. Leemann, N. Toropovs, A. Malekos, M.M. Koebel, P. Lura, Study of physical properties and microstructure of aerogel-cement mortars for improving the fire safety of high-performance concrete linings in tunnels, Cem. Concr. Compos. 104 (2019) 103414.

[15] Y. Ding, S. Liu, Y. Zhang, A. Thomas, The investigation on the workability of fibre cocktail reinforced self-compacting high performance concrete, Constr. Build. Mater. 22 (2008) 1462-1470.

[16] Y. Ding, C. Azevedo, J.B. Aguiar, S. Jalali, Study on residual behaviour and flexural toughness of fibre cocktail reinforced self compacting high performance concrete after exposure to high temperature, Constr. Build. Mater. 26 (2011) 21-31.

[17] Y. Ding, W. Zeng, Q. Wang, Y. Zhang, Topographical analysis of fractured surface roughness of macro fiber reinforced concrete and its correlation with flexural toughness, Constr. Build. Mater. 235 (2020) 117466.

[18] J. Zhang, C. Gong, Z. Guo, M. Zhang, Engineered cementitious composite with characteristic of low drying shrinkage, Cem. Concr. Res. 39 (2009) 303-312.

[19] J. Zhang, X. Ju, Investigation on stress-crack opening relationship of engineered cementitious composites using inverse approach, Cem. Concr. Res. 41 (2011) 903-912.

[20] BS EN 197-1, Cement Part 1: Composition, specifications and conformity criteria for common cements, British Standards Institution, (2011). 
[21] ASTM C666/C666M-03, Standard Test Method for Resistance of Concrete to Rapid Freezing and Thawing, American Society for Testing and Materials. (2003).

[22] S. Yi, T. Hyun, J. Kim, The effects of hydraulic pressure and crack width on water permeability of penetration crack-induced concrete, Constr. Build. Mater. 25 (2011) 2576-2583.

[23] V. Picandet, A. Khelidj, H. Bellegou, Crack effects on gas and water permeability of concretes, Cem. Concr. Res. 39 (2009) 537-547.

[24] S. Erdem, M.A. Blankson, Fractal-fracture analysis and characterization of impact-fractured surfaces in different types of concrete using digital image analysis and 3D nanomap laser profilometery, Constr. Build. Mater. 40 (2013) 70-76.

[25] Y. Xin, K.J. Hsia, D.A. Lange, Quantitative Characterization of the Fracture Surface of Si Single Crystals by Confocal Microscopy, Journal of the American Ceramic Society. 78 (1995) 3201-3208.

[26] T. Ficker, D. Martišek, H.M. Jennings, Roughness of fracture surfaces and compressive strength of hydrated cement pastes, Cem. Concr. Res. 40 (2010) 947-955.

[27] A. Carpinteri, B. Chiaia, S. Invernizzi, Three-dimensional fractal analysis of concrete fracture at the meso-level, Theoretical and Applied Fracture Mechanics. 31 (1999): $163-172$.

[28] W. Zhang, Z. Ning, Z. Yao, Effect of flexural impact on freeze-thaw and deicing salt resistance of steel fiber reinforced concrete, Mater. Struct. 49 (2016) 1-8.

[29] G. Tiberti, F. Minelli, G.A. Plizzari, F.J. Vecchio, Influence of concrete strength on crack development in SFRC members, Cem. Concr. Compos. 45 (2014) 176-185.

[30] J. Nam, G. Kim, B. Lee, R. Hasegawa, Y. Hama. Frost resistance of polyvinyl alcohol fiber and polypropylene fiber reinforced cementitious composites under freeze thaw cycling, Compos. Part B: Eng. 90 (2016) 241-250. 
605 [31] Y. Zhao, L. Wang, Z. Lei, X. Han, J. Shi, Study on bending damage and failure of basalt 606 fiber reinforced concrete under freeze-thaw cycles, Constr. Build. Mater. 163 (2018)

607

608

609

610

611

612

613

614

615

616

617

618

619

620

621

622

623 460-470.

[32] M. Armandei, E.S.S. Filho, Correlation between fracture roughness and material strength parameters in SFRCs using 2D image analysis, Constr. Build. Mater. 140 (2017) 82-90.

[33] A. Yan, K.R. Wu, D. Zhang, W. Yao, Effect of fracture path on the fracture energy of high-strength concrete, Cem. Concr. Res. 31 (2001) 1601-1606.

[34] M.A. Issa, M.S. Islam, A. Chudnovsky, Fractal dimension-a measure of fracture roughness and toughness of concrete, Eng. Fract. Mech. 70 (2003) 125-137.

[35] W. Cai, G. Cen, H. Wang, Fracture Surface Fractal Characteristics of Alkali-Slag Concrete under Freeze-Thaw Cycles, Adv. Mater. Sci. Eng. 2017(2017) 1-9.

[36] V. Mechtcherine, Fracture mechanical behavior of concrete and the condition of its fracture surface, Cem. Concr. Res. 39(2009) 620-628.

[37] T. Petchsingto, Z.T. Karpyn, Deterministic Modeling of Fluid Flow through a CT-scanned Fracture Using Computational Fluid Dynamics, Energy Sources, Part A: Recovery, Utilization, and Environmental Effects. 31(2009) 897-905.

[38] V. Rasouli, A. Hosseinian, Correlations Developed for Estimation of Hydraulic Parameters of Rough Fractures Through the Simulation of JRC Flow Channels, Rock Mech. Rock Eng. 44(2011) 447-461. 